\title{
Bridging Data and Decision Making: Development of Techniques for Improving the HIV Prevention Community Planning Process
}

\author{
Richard A. Jenkins, ${ }^{1,7}$ Ann Robbins, ${ }^{2}$ Kevin Cranston, ${ }^{3}$ Kim Batchelor, ${ }^{4}$ Anne C. Freeman, ${ }^{4}$ \\ Abigail R. Averbach, ${ }^{3}$ Hortensia Amaro, ${ }^{5}$ Allison C. Morrill, ${ }^{5}$ Susan M. Blake, ${ }^{6}$ \\ Jennifer A. Logan, ${ }^{3}$ and James W. Carey ${ }^{1}$
}

\begin{abstract}
Assessments of community planning in Massachusetts and Texas were used to develop tools for increasing the use of data by HIV prevention community planning groups (CPGs) and prevention providers while also increasing participation of CPG members. Barriers to data use included organizational problems in CPGs (e.g., lack of clear procedures, distrust of peers and leadership) and technical assistance needs for CPG members and researchers who provide data. The absence of data relevant to local epidemics was another barrier. Specific linkages are provided between the assessments of these needs and the development of a technical assistance tools (e.g., websites, templates for data presentation, experiential involvement in data use) and strategies for organizational change in CPGs, as well as efforts to better use available data and create or identify new sources of local data.
\end{abstract}

KEY WORDS: community planning; prevention; policy; intervention.

\section{INTRODUCTION}

HIV prevention community planning was introduced through supplemental guidance published by the Centers for Disease Control and Prevention (CDC) in 1993 (CDC, 1993). This effort to facilitate evidence-based planning and community input resulted from consultations with a variety of governmental and nongovernmental agencies and became a requirement for $\mathrm{CDC}$ funding of state and territorial

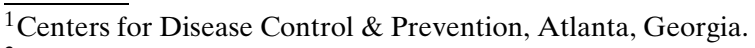

${ }^{2}$ Texas Department of Health, Austin, Texas.

${ }^{3}$ Massachusetts Department of Public Health, Boston, Massachusetts.

${ }^{4}$ University of Texas Southwestern Medical Center, Dallas, Texas.

${ }^{5}$ Northeastern University, Boston, Massachusetts.

${ }^{6}$ George Washington University, Washington, District of Columbia.

${ }^{7}$ Correspondence should be directed to Richard A. Jenkins, Division of HIV/AIDS Prevention, Centers for Disease Control and Prevention, 1600 Clifton Road, NE, Mailstop E-37, Atlanta, Georgia 30333; e-mail: rgj2@cdc.gov.
}

HIV prevention programs in 1994. There have been subsequent revisions of the guidance (CDC, 1998, 2003) in response to feedback and changes in prevention policy. In brief, the basic steps of community planning include assessment of present and future HIV epidemics in defined populations, assessment of community resources, identification of unmet needs, and development of comprehensive HIV prevention plans in which priorities are determined for populations and appropriate interventions are identified (in the past intervention prioritization also was a step). The prevention plans then serve as the basis for jurisdictions' applications to CDC for prevention funds (Valdiserri et al., 1995).

The initial guidance for HIV prevention community planning (CDC, 1993; Academy for Educational Development, 1994) focused on the establishment of community planning groups (CPGs) by jurisdictional health departments to provide community input into the determination of community priorities and other planning steps. The guidance intentionally has been flexible so that planning can 
be responsive to local conditions and resources (Valdiserri et al., 1995). CPG membership is meant to include participation from a variety of stakeholders including: health departments, non-governmental organizations, and advocates for at-risk and affected populations (Valdiserri et al., 1995). The core tasks of community planning, prioritization of populations and selection of interventions, are expected to be based on documented need, with attention to culturally relevant information, and local resources.

There are many potential barriers to making optimal use of data in any planning process, particularly one that involves groups, as in the case of HIV prevention community planning (see Jenkins and Carey, 2005 for a review of relevant research on decision making). Because community planning uses databases that have been developed for other purposes (e.g., disease surveillance), CPG members may find themselves having difficulty applying these data to their core planning objectives, and the lack of familiarity with community planning goals on the part of researchers who provide these data may compound these problems. When data are limited or poorly explained, their interpretation tends to be shaped by personal biases or "rules of thumb" or heuristics which may distort the meaning of data (Tversky and Kahneman, 1974). Decision making in a group means that group process and intra-group relations become important factors, as well. A recurring issue in community planningtype efforts is the clash between the differing worldviews of professional researchers and those of lay persons or professional policy planners who lack research experience (e.g., Rothman, 1974; Weiss, 1980).

\section{Purpose of this Paper}

While there has been surprisingly little effort to relate data use barriers to the broad literature on decision making, many of the barriers mentioned here are well documented in relation to HIV community planning (Jenkins et al., 2005). Despite this ample documentation, few concrete methods or tools for improving data use and decision making have been offered. Our own experience is that jurisdictions are often able to identify data deficits, problems in the facilitation of groups, and limitations to available technical assistance, but have difficulty taking concrete steps to address these problems. The purpose of this paper is to review our case study data and illustrate how the self-study of HIV prevention planning in Texas and Massachusetts was used to develop locally useful tools for addressing barriers to data use in HIV prevention decision making.

Massachusetts and Texas participated in a CDC-funded project to assess and address the barriers to using data for HIV prevention community planning. These two states are both characterized as moderate prevalence jurisdictions (CDC, 2001), although both have considerable geographic variation in prevalence and transmission risks. Texas has a decentralized planning structure with six regional CPGs, although the Texas Department of Health has primary responsibility for providing data to each CPG. Massachusetts has a single CPG for the entire state. CPG members in both states tend to come from service provider organizations, although the educational level of Massachusetts CPG members tends to be higher than in Texas, with more members having graduate degrees (Amaro et al., 2005; Batchelor et al., 2005). Massachusetts has had more resources for supplementing the planning process in the past and more varied data sources than Texas; however, Texas has more data sources available than many smaller states, although there is some variation in the availability of different data within Texas. The core assessments of CPG members' impressions of the planning process were similar in both states (Amaro et al., 2005; Batchelor et al., 2005); however, the differences in planning structure led to the use of some different methodologies and differences in emphasis in terms of efforts to increase the use of data in the planning process.

Each jurisdiction assessed data use, attitudes about different types of data, perceptions of the community planning environment, and CPG member attributes such as technical skill in using data. Massachusetts placed more emphasis on organizational factors, while Texas extended its assessment to include prevention providers. Below, we describe each site's efforts to apply their formative work to the development of tools and interventions to improve the use of data for decision making in their jurisdiction. The formative research is described in summary form here, however, more details regarding participants, methods, instruments, and findings are provided in Amaro et al. (2005) and Batchelor et al. (2005).

\section{CASE STUDY 1: MASSACHUSETTS}

\section{Background and Method}

The formative data collection in Massachusetts has been described in detail elsewhere in this issue 
(Amaro et al., 2005). In brief, assessment of Massachusetts' CPG was conducted by social scientists from Northeastern University (who initially were based at Boston University), in collaboration with an external consultant from George Washington University. In-depth interviews were conducted with CPG members to understand the extent to which members reported that their decisions were informed by data, and to identify information regarding facilitators and barriers to data use. Specifically, the interviews asked about data inputs (quality, completeness, amount of data received; quality of data presentations), the structure and function of the CPG (member role, role of the CPG, group process, tasks) and data-related skills (self-assessed, along with assessments of other CPG members' skills, in general).

\section{Participants}

Amaro et al., 2005 describe the sampling methods in depth. Briefly, CPG membership was stratified by levels attendance at past CPG meetings (based upon health department records). Of those sampled, 19 participated in the interviews (84\% of those sampled; $43 \%$ of all eligible CPG members). The sample generally mirrored the composition of the entire CPG membership in terms of gender, race/ethnicity, and experience in the field. Members in the sample varied in their educational levels, job types, and the degree to which the Massachusetts Department of Public Health (MDPH) funded their workplace. Most members of the sample worked for agencies that were fully funded by MDPH (11 of the 19), while four worked at partially MDPH funded-agencies, and four others worked for independently funded organizations.

\section{Procedures}

Oral informed consent was obtained. Interviews were audio-recorded, transcribed in full with the transcripts reviewed for accuracy. Identifying information was altered or omitted to protect participant confidentiality. The protocol was submitted for CDC and Boston University IRB review, but was deemed to be exempt from formal review because the project was considered program evaluation and programmatic improvement, rather than "research". Nonetheless, normal informed consent procedures and guidelines were followed. See Amaro et al. (2005) for specific details regarding enrollment.

\section{Instrument and Analysis}

Semi-structured, open-ended interview questions explored different aspects of the population prioritization in 1999 (the most recent planning task): perceived support for the prioritization task, clarity of the task, leadership/group dynamics, and data used to inform the prioritization decision (along with the rationale and relative weights for individual data sources). Similar questions were asked about hypothetical planning tasks (e.g., prioritization of populations, situations where professional experience seemed inconsistent with available data) and factors that might inform their decisions in those situations. A codebook was developed based upon research literature-informed concepts, as well as themes derived from participant responses. One coder, the interviewer, reviewed and coded all transcripts and used NVivo (QSR International Pty., Melbourne, Victoria, Australia) qualitative data analysis software to sort coded material. Content analysis and some narrative analysis were performed. See Amaro et al. (2005) for additional details regarding data collection instruments and analysis.

\section{Results: Findings and the Efforts that Grew from Them}

\section{Data Inputs}

Quality and Completeness (Table I). In the interviews, most CPG members indicated that the data provided by MDPH and its research contractors were of "good" quality. However, data were not seen as always being complete because some populations were understudied or were thought by CPG members to experience substantial underreporting. These included populations with obvious risk factors such transgendered persons and immigrant populations where numbers of cases have grown in recent years. Many members believed that DPH and contractors selected data for presentation that supported a DPH or contractor agenda (e.g., to give greater weight to a specific population) and, thus, felt skeptical about the completeness of material available for decision-making.

P: And, you know, there are certain groups that I think need to be up there on the agenda, such as people not born in the United States or transgenders who have an outrageous rate. 
Table I. Massachusetts: Findings from Formative Research and Resultant Interventions

\begin{tabular}{|c|c|}
\hline Findings & Interventions \\
\hline \multicolumn{2}{|l|}{ Data inputs } \\
\hline $\begin{array}{l}\text { Quality and completeness: Quality seen as good but often seemed to } \\
\text { be incomplete, selective }\end{array}$ & $\begin{array}{l}\text { 1. Improve prioritization and responsiveness to requests } \\
\text { for data }\end{array}$ \\
\hline Amount of data was too much to process & 2. Improve appropriateness and timeliness of data \\
\hline $\begin{array}{l}\text { Presentations: Seen as boring and not accessible; their relevance to } \\
\text { task often was not apparent }\end{array}$ & $\begin{array}{l}\text { collection efforts } \\
\text { 3. Improve quality of data presentations }\end{array}$ \\
\hline \multicolumn{2}{|l|}{ Organizational structure of the $C P G$} \\
\hline $\begin{array}{l}\text { Member role: Members themselves as representing their } \\
\text { communities }\end{array}$ & $\begin{array}{l}\text { 1. Improve participation, involvement, and trust in } \\
\text { decision making }\end{array}$ \\
\hline $\begin{array}{l}\text { MPPG role: Most understood their roles but some wanted greater } \\
\text { impact. Some were unclear about the implications of decisions; }\end{array}$ & $\begin{array}{l}\text { 2. Increase clarity of process, to ensure understanding and } \\
\text { participation }\end{array}$ \\
\hline frustrated when recommendation were not followed & $\begin{array}{l}\text { 3. Increase population and intervention prioritization } \\
\text { decision-making frequency and reduce the time lag } \\
\text { between decisions following exposure }\end{array}$ \\
\hline \multicolumn{2}{|l|}{ Member characteristics } \\
\hline \multicolumn{2}{|l|}{$\begin{array}{l}\text { The planning process: Time limits were seen as having constrained } \\
\text { discussion and participation }\end{array}$} \\
\hline $\begin{array}{l}\text { Trust and multiple roles: Confusion about past events contributes to } \\
\text { distrust of DPH. Some perceived a co-chair from DPH staff as } \\
\text { having conflicts of interest }\end{array}$ & $\begin{array}{l}\text { 1. Increase member ability to participate, understand and } \\
\text { apply behavioral data to population and intervention }\end{array}$ \\
\hline $\begin{array}{l}\text { Data-related skills: Individual members described their own } \\
\text { data-related abilities as superior to other members; suggested that } \\
\text { members get more training or that presentations be modified. } \\
\text { Actual data-using competence was difficult to be assessed through } \\
\text { self-report }\end{array}$ & decision making \\
\hline
\end{tabular}

To improve the timeliness and appropriateness of data, a standardized form for making data requests has been created to respond to data requests generated at the level of population-based discussion groups, which are prioritized by Work Plan Committee (responsible for planning the content of CPG meetings), while responsiveness to these requests is monitored by the Steering Committee (which focuses on managing process within the CPG).

Amount of Data (Table I). Some members believed that there were times when too much data were presented and that this impaired the group's ability to discuss the implications of the data, a key component of a satisfying decision-making process (sample quote: "Sometimes too much [data] in very little time").

Presentations (Table I). Most CPG members indicated that scientific data presentations were boring, not always conceptually accessible to all members, and that examples made for better presentations. Many members requested that presentations of scientific data be illustrated with illustrative cases or other examples. A few members indicated a lack of comprehension about the relationship of individual presentations to the group's purpose.

Based on these findings, two related steps were taken to improve the quality of data presentations:
(1) MDPH staff developed guidelines for presentations that took into account members' comments and were approved by the CPG Steering Committee; and (2) a standardized presentation format was developed to facilitate implementation of the guidelines. The guidelines and related materials walk presenters through the steps needed to create presentations and help them make connections between their data and CPG goals. In addition, a process evaluation form was developed so that CPG members could rate the quality of data presentations.

\section{Organizational Structure of the $C P G$}

Roles of Individuals and Roles of the CPG (Table I). Many members believed that their role entailed representation of their community's experience and some members believed that they were selected for the CPG because of their ability to represent a particular community. Most members believed that the group was supposed to be composed of representatives of affected and at risk communities who could update $\mathrm{MDPH}$ on the nature and scope of HIV risk and successful approaches to intervention in their populations. Surprisingly, CPG members did not believe that 
the need to advocate for one's community carried more weight than research data in the majority of their decisions. Members reported that they used their own experience (professional and personal) to assess the validity and comprehensiveness of the scientific data, yet they centered their critiques of the planning process on the data, and did not assert that experience should be the basis for decision-making.

The vast majority of respondents appeared to have a clear understanding of the CPG's stated purpose, as an advisory body to the MDPH. A few members wanted the group to have more influence on administrative decisions or a greater impact on HIV prevention planning. Even so, some frustration about the CPG stemmed from feelings that its decisionmaking role was limited.

\section{P: I honestly believe the purpose, [of the MPPG] would be that we, we don't demand but we ask. We bring across the table as members as leaders what the communities need, what the agencies need to provide better services.}

A few members seemed unclear about the implications CPG's decisions. These members indicated that they may have made decisions regarding the HIV Prevention Plan based on misinformation about the consequences of decision-making.

\begin{abstract}
P: The other thing that went through my mind was that we [the CPG], does try to be so politically correct when it comes to minority populations. Especially that we put so many subcategories in every category that given the level of funding that was available, we might not be able to cover everybody anyway.

\section{P: Prioritization, to my mind, is about leftover monies. I think people are pushing for their own agendas.}

Based on these findings and its ongoing internal review, the CPG reorganized itself and changed its operating procedures. It attempted to increase member participation and involvement in decisionmaking by organizing itself into three primary governance groups: the Steering Committee (responsible for managing CPG meeting process and including the CPG co-chairs), the Work Plan committee (responsible for planning the content of CPG meetings), and the Membership committee (responsible for recruiting and screening prospective members). Previously, a steering committee which, included co-chairs and several at-large members, had had the authority that had been given to these three bodies. The previous Steering Committee's broad scope and its inclusion of several MDPH staff had been sources of concern in the assessment. New members were selected for the CPG, approved by the current membership and an orientation was provided. "Population groups" were organized to discuss the presentations at each meeting as a way of promoting the processing of data close to the time of its presentation. The composition of these groups was based on individual members' involvement with specific populations at-risk (e.g., men who have sex with men, injection drug user, etc.) so they could address issues of greatest importance to their constituencies. In addition, the groups were designed to facilitate discussion of data presentations, especially with respect to their relevance to issues in key population categories.

The Planning Process/Task (Table I). Most members felt that discussion was essential to decision-making and that adequate time for discussion was sometimes not supported by the ways in which meetings were structured. Time for discussion was a key component of members' concepts of participation, hence, frustration occurred because limited discussion time inhibited participation.

P: I don't know any meeting I ever attended, any group, that had adequate time to really think through issues, talk them through and really come to some sound decisions, which is kind of a scary thing about our work.

Several steps were taken to increase clarity of the planning process and to ensure understanding and participation. A revised policies and procedure manual was created to clarify decision-making processes and procedures (e.g., consensus, voting procedures, procedures for decisions according to whether they pertain to CPG structure or content areas like prioritization). A process evaluation form was developed for members to provide feedback regarding their satisfaction with meeting processes and provide a way to solicit agenda items.

To make participation more relevant and reduce the time lag between decisions following exposure to data presentations, the Work Plan Committee now develops a schedule of presentations with reference to key decisions to be made. This schedule provides an articulated work plan that covers an 18-month period and links exposure to data more closely in time to CPG decision-making. The Steering Committee creates a monthly agenda based on this schedule and monitors implementation.

Prioritization processes used in other jurisdictions were reviewed, and a 5-year prioritization 
planning cycle has been proposed for approval and use by the CPG. Revised procedures and guidelines for developing population and intervention prioritization plans (e.g., identification of key indicator variables, development of worksheets to facilitate note taking) have been formulated by an ad hoc policy and procedures committee, reviewed by the Steering Committee, and are being pilot-tested for use in subsequent years.

Trust and Multiple Roles (Table I). The MDPH Director of Planning and Evaluation's dual role as DPH staff and co-chair of the CPG was perceived by some CPG members as a conflict of interest and gave the impression that MDPH was in charge of the group. As mentioned previously, the executive functions of the CPG were distributed across several committees, which reduced the power invested in any one committee and permitted more opportunities for CPG members to be involved in governance.

\section{Member Characteristics}

Data-Related Skills (Table I). Most Massachusetts CPG members described their own use of data and ability to comprehend scientific evidence as superior to that of other CPG members. Many members suggested that presentations be made less technical and that members get more training or technical assistance regarding interpretation of data, although this tended to be directed at other members of the CPG.

\footnotetext{
P: I wouldn't expect people to understand some of this stuff just coming in. But, they ought to understand if they're going to be discussing it a year and two years in.

P: I can give you some of the people who are higher up and get some training in how to communicate with the lower people. [I: When you say higher up...J I mean like the doctorates, you know, the prevention specialists, who study methodology all day long.
}

A major component of Massachusetts' efforts to improve the planning process has been a set of interventions to increase members' ability to participate in data-based discussions and increase their ability to understand and apply data to the prioritization of populations and interventions. The Membership Task Force has reviewed models for training in the use of behavioral data and has been developing training systems. Some of this has involved consideration of materials from the other study site (e.g., a training module used by Texas). These will be reviewed and approved by Steering Committee, integrated into monthly meeting agendae, with MDPH support. In addition, the "population groups" deliberate on how data presentations apply to priority subpopulations and interventions immediately after presentations.

Massachusetts also committed resources to provide technical assistance for researchers who present to the CPG. This includes providing presentation templates with standard formats for the presentation of particular kinds of data (e.g., particular graphics for representing population groups), standard questions to be addressed (i.e., guiding presenters toward the CPG's core tasks, helping explain uses and limitations of data, helping triangulate among data sources) and direct feedback and assistance is being provided to help make each presentation responsive to the CPGs' needs.

\section{CASE STUDY \#2: TEXAS}

\section{Background and Method}

Data collection methods for the formative assessment in Texas are detailed elsewhere (Batchelor et al., 2005). In brief, members of Texas' six regional CPGs (known as HIV Prevention Planning Councils), as well as the State's prevention providers, participated in a formative assessment of the use of behavioral data. The assessment was considered exempt from human subjects requirements by the Texas Department of Health IRB, which considered the work to be program improvement/evaluation, however, standard informed consent procedures were followed with all participants. The CPG member assessment (conducted by the Health Education and Training Centers Alliance of Texas [HETCAT]) will be discussed first, followed by the assessment of the prevention providers (conducted by the University of Texas Southwestern School of Medicine at Dallas [UT Southwestern]).

\section{Texas CPG Assessment (Sample and Instrument)}

This assessment involved qualitative, face-toface interviews with CPG members during late 2000 and early 2001 The interviews were audio-taped (after receiving informed consent) and transcribed. Respondents needed to be current CPG members and to have participated in the development of the 
most recent community plan for their region. There was a $64 \%$ participation rate and the demographic composition of the sample was largely reflective of the characteristics of the eligible CPG members.

Interview topics included: overall feelings about participation in community planning, views on the requirement that CPG decisions be "data driven," descriptions of how their CPGs had used data to prioritize populations and select interventions, the types of data available for use in decision making, the value of these data to them as CPG members and decision makers, and the perceived gaps in available behavioral data. The interview transcripts were coded by CDC staff in Atlanta using CDC EZText software (Carey et al., 1998).

An archival document review (including HIV Prevention Plan, planning group minutes, bylaws, orientation manuals and process evaluation results) was used to explore salient issues of the CPG's decision making processes.

\section{Texas Prevention Provider Assessment} (Sample and Instrument)

A mail survey was used to sample staff in community-based agencies and local health departments ("prevention providers") funded by TDH. Of these, $37 \%$ were returned and analyzed. Respondents included health educators, outreach workers, prevention counselors, disease intervention specialists, supervisors and those who wrote the grants for health education, risk reduction and prevention counseling/partner elicitation programs. Demographic and other background characteristics are summarized in Batchelor et al. (2005). A quantitative approach was used with prevention providers because of their large number and the diversity of services and populations they served.

UT Southwestern staff also conducted semistructured interviews via telephone with supervisors from the provider agencies who had indicated their availability when they completed the provider survey. The supervisor interviews were conducted to follow-up major findings from the survey and also asked about ways that information and training concerning new interventions were provided to staff. Survey responses were analyzed with SPSS Version 10 (SPSS, Inc., Chicago, IL). Supervisor interviews were analyzed with NUD* IST Version 4 (QSR International, Pty., Melbourne, Victoria, Australia).

\section{Results: Findings and Efforts that Grew from Them}

\section{Findings from CPG Members}

Value of the data driven nature of $C P G$ decision making (Table II). Most CPG members found the emphasis on data to be helpful, especially for identifying populations to be targeted, but some members cited gaps in behavioral data, particularly for ethnic and racial minorities, substance abusers, youth, and men who have sex with men. Some respondents had concerns that the data and decision making processes could be manipulated by TDH or by CPG members for their own agendas. Some members related that this had occurred in their CPG and that it had led to negative outcomes (e.g., the data did not include populations believed to be at risk).

TDH responded to these findings by increasing local capacity for data use through the involvement of CPGs in collecting and analyzing local needs assessment data (with technical assistance from TDH). This provides a "hands on" understanding of how to critically use data while also addressing the expressed desire for more local data. In addition, the Epidemic Profile (which serves as the basis for regional epidemiological profiles) has been revised to provide data breakdowns by "Morbidity Analysis Zones" (i.e., high and low morbidity areas) within their regions. The Epidemic Profile now also includes risk behavior data from the recently revised counseling and testing data system, and this is broken down by the same morbidity zones.

Opinions about value of different types and sources of data (Table II). CPG members most frequently mentioned the following as the data sources they valued most: data from TDH, program effectiveness data, morbidity information from the epidemiological profile, and information on risk behaviors. There was very little use of other behavioral data. Peers and networking were the primary sources of information, and data from research articles and journals were mentioned very seldom. The majority of the respondents were confident that the data they used represented their local epidemic. This was despite the concerns about the availability of data for specific populations that were noted previously. To address data gaps, CPGs were provided with more locally focused data on HIV morbidity in their areas and the additional data on characteristics of HIV infected individuals (the Epidemic Profile and counseling data, sorted by morbidity zone and described in 
Table II. Texas: Findings from Formative Research and Resultant Interventions (CPG)

\begin{tabular}{|c|c|}
\hline Findings & Associated interventions \\
\hline \multicolumn{2}{|l|}{ Value of data driven nature of CPG decision making } \\
\hline $\begin{array}{l}\text { - Data-driven approach helpful, in identifying populations } \\
\text { - Gaps in behavioral data for minorities and some risk } \\
\text { groups }\end{array}$ & $\begin{array}{l}\text { 1. Create capacity in local providers/CPG members to plan and } \\
\text { conduct rapid assessments and needs assessments to fill future data } \\
\text { gaps }\end{array}$ \\
\hline \multirow[t]{2}{*}{$\begin{array}{l}\text { - Concerns how data and decision making process can be } \\
\text { manipulated }\end{array}$} & $\begin{array}{l}\text { 2. Regional epidemiological profiles supplemented with breakdowns } \\
\text { for high and low morbidity zones, and counseling and testing data }\end{array}$ \\
\hline & 3. Raw morbidity data made available to CPGs \\
\hline \multicolumn{2}{|l|}{ Opinions about the value of different types and sources of data } \\
\hline $\begin{array}{l}\text { - Health dept data, morbidity information, and risk } \\
\text { behavior data were the most valued }\end{array}$ & $\begin{array}{l}\text { 1. CPGs provided with data on high and low morbidity zones and } \\
\text { additional risk behavior data (see above) }\end{array}$ \\
\hline - Concerns about the timeliness and trustworthiness of data & $\begin{array}{l}\text { 2. CPGs provided with information on effective interventions and } \\
\text { training to adapt these interventions }\end{array}$ \\
\hline $\begin{array}{l}\text { - Low understanding of behavioral data apart from } \\
\text { morbidity } \\
\text { - Peers are most valued source of information, research } \\
\text { journals seldom accessed }\end{array}$ & $\begin{array}{l}\text { 3. Regionally dispersed group of prevention providers given intensive } \\
\text { training on assessment, theory, and strategies for identifying and } \\
\text { tailoring interventions. They acted as peer leaders in CPG meetings } \\
\text { around these topics }\end{array}$ \\
\hline \multicolumn{2}{|l|}{ Data that CPGs would like to use } \\
\hline \multirow{4}{*}{$\begin{array}{l}\text { - Would like: } \\
\circ \text { qualitative data, } \\
\circ \text { morbidity data, } \\
\circ \text { data on risk behaviors, } \\
\circ \text { information on determinants of HIV risk, } \\
\circ \text { more information about interventions }\end{array}$} & $\begin{array}{l}\text { 1. Locally focused needs assessments were implemented by each CPG } \\
\text { in their region using a standard quantitative survey }\end{array}$ \\
\hline & $\begin{array}{l}\text { 2. Regional epidemiological profiles format revised (see above) to } \\
\text { include more risk behavior data }\end{array}$ \\
\hline & $\begin{array}{l}\text { 3. Fact sheets and other information provided regarding effective } \\
\text { interventions }\end{array}$ \\
\hline & $\begin{array}{l}\text { 4. Prevention providers given intensive training on assessment, theory, } \\
\text { and identification/tailoring interventions (see above) }\end{array}$ \\
\hline $\begin{array}{l}\text { TA that CPGs would like to have provided to them } \\
\text { - Want more data summaries } \\
\text { - Increased access to the data }\end{array}$ & $\begin{array}{l}\text { 1. Regional epidemiological profiles (described above) posted on TDH } \\
\text { web site and provided to the CPG in advance of prioritization } \\
\text { processes }\end{array}$ \\
\hline $\begin{array}{l}\text { - More time to work with the data } \\
\text { - More TA and training on working with data }\end{array}$ & $\begin{array}{l}\text { 2. "New member" training module was updated and delivered to CPG } \\
\text { members }\end{array}$ \\
\hline use of personal experience & 1. Need to have more intensive involvement from TDH and existing \\
\hline Who the CPG would like to have assist them in use of data & TA providers, as well as need to identify TA providers to join CPGs \\
\hline $\begin{array}{l}\text { - TDH staff, specialists, academics, TA providers } \\
\text { - Expertise and ability to explain the data clearly are most } \\
\text { important qualities }\end{array}$ & $\begin{array}{l}\text { 2. Efforts to increase data using capacity of prevention providers had } \\
\text { spillover effects into CPGs where they also participate and actas } \\
\text { peer leaders }\end{array}$ \\
\hline - Most comfortable with information coming from peers & $\begin{array}{l}\text { 3. Efforts to increase available data (described previously) and involve } \\
\text { CPGs in the collection and analysis of their periodic needs } \\
\text { assessments (also described previously) }\end{array}$ \\
\hline
\end{tabular}

the previous paragraph). CPGs also were provided with summary information on behavioral interventions with evidence of effectiveness (i.e., programs descriptions and information about their effectiveness), and given training on ways to use theory and data to adapt these effective interventions to their populations of interest.

Data that the CPG would like to use (Table II). CPG members expressed interest in making more use of focus group/key informant data, and wanted additional information on local morbidity, as well as more data on risk behaviors and behavioral determinants of HIV risk, and further information on evidence-based interventions. The locally focused needs assessments implemented after the formative work (noted above) provided a way to address some of these issues, although they did not include qualitative data or additional disease morbidity information. Capacity building for qualitative data collection was concentrated on a group of prevention providers who later acted as peer leaders in their service communities and on their CPGs. The qualitative assessments that came from these providers' efforts provided additional information on determinants of behavioral risk that was used by the CPGs. 
Assistance in using data (Table II). CPG members wanted to see more data summaries, have increased access to the data, have more time to work with the data, receive more support from staff and others are familiar with the data, and receive more training in the use of data. They also felt that more orientation on the planning process and data use was needed for new CPG members. In response to these findings, the regional epidemic profiles were posted on the TDH web site and were provided to the CPG well in advance of prioritization processes; unfortunately, it has continued to be difficult to offer a uniformly high level of local epidemiological assistance and it has been unclear how much these changes were able to affect the prioritization process. To address training and orientation concerns, a module for new member orientation was revised and presented to the CPGs.

Who would the CPG like to have assist them in use of data? (Table II). The respondents nominated TDH staff, specialists in specific content areas (e.g., epidemiologists, behavioral scientists), academics, and technical assistance providers like UT Southwestern. They indicated that the most important characteristics of these individuals would be demonstrated expertise, followed by the ability to explain data clearly.

The TA needs, especially the epidemiology expertise, have remained difficult to address. There is considerable variation between planning regions in the availability of potential TA providers or experts who are able to serve as CPG members. Efforts to improve available data, the involvement of CPG members in the needs assessments (mentioned previously), and the training of prevention providers to serve as peer leaders have been efforts to fill these gaps.

\section{Prevention Provider Findings}

Types of interventions in the field (Table III). When asked about the types of interventions they fielded, few described purposeful, skills-building interventions, and only $1 \%$ mentioned using behavioral science or theory to shape interventions. The remainder described client education or distribution of materials. This finding led to a variety of efforts to increase the awareness of interventions with proven effectiveness, including

Table III. Texas: Findings from Formative Research and Resultant Interventions (Prevention Providers)

\begin{tabular}{|c|c|}
\hline Findings & Associated interventions \\
\hline \multicolumn{2}{|l|}{ Types of interventions in the field } \\
\hline $\begin{array}{l}\text { - Few described skills-building interventions } \\
\text { - } 1 \% \text { mentioned using behavioral science/theory to } \\
\text { shape interventions }\end{array}$ & $\begin{array}{l}\text { 1. Provided intensive training and TA on relevant topics to small group of } \\
\text { prevention provider staff providers regarding theory, logic modeling, } \\
\text { and methods for intervention selection and adaptation }\end{array}$ \\
\hline $\begin{array}{l}\text { - Most described client education or distribution of } \\
\text { materials }\end{array}$ & 2. Developed a web site with summaries of evidence-based interventions \\
\hline \multicolumn{2}{|l|}{ Where they get intervention ideas } \\
\hline - Providers get interventions from each other; & 1. Intense training to prevention providers (described above) \\
\hline $\begin{array}{l}\text { - Research literature and theory-driven intervention } \\
\text { rarely mentioned }\end{array}$ & $\begin{array}{l}\text { 2. Web-based resources developed including fact sheets regarding } \\
\text { effective interventions (described above) and assessment guide to } \\
\text { permit collection of formative data }\end{array}$ \\
\hline \multicolumn{2}{|l|}{$\begin{array}{l}\text { Kinds of information that providers feel help them do } \\
\quad \text { better work }\end{array}$} \\
\hline $\begin{array}{l}\text { - Weak links articulated between choice of } \\
\text { intervention strategy and articulation of factors } \\
\text { that influence risk among clients }\end{array}$ & $\begin{array}{l}\text { 1. Provided relevant training to a subset of providers (described above) } \\
\text { 2. Developed web resources (fact sheets and assessment materials } \\
\text { described above) }\end{array}$ \\
\hline & $\begin{array}{l}\text { 3. Established an email group of providers to dialogue } \\
\text { on intervention issues }\end{array}$ \\
\hline \multicolumn{2}{|l|}{$\begin{array}{l}\text { Kinds of data currently used by providers to make } \\
\quad \text { programming decisions }\end{array}$} \\
\hline $\begin{array}{l}\text { - Most commonly used types of data were HIV risk } \\
\text { behavior, disease statistics, and information from }\end{array}$ & $\begin{array}{l}\text { 1. Guide for conducting rapid community assessments developed and } \\
\text { made available on website }\end{array}$ \\
\hline conference presentations & 2. Intensive training given to prevention providers on effective \\
\hline $\begin{array}{l}\text { - Cost effectiveness, research journals, and } \\
\text { qualitative data used less often }\end{array}$ & $\begin{array}{l}\text { interventions and behavioral theory (described above) including use of } \\
\text { the guide }\end{array}$ \\
\hline $\begin{array}{l}\text { - Supervisors indicated that they would like to use } \\
\text { community assessment but rarely do }\end{array}$ & $\begin{array}{l}\text { 3. Training emphasized use of behavioral data to identify determinants of } \\
\text { behavior and using these data to help identify and adapt interventions } \\
\text { 4. Epidemic profile data made available on TDH website }\end{array}$ \\
\hline
\end{tabular}


a web site with descriptions of effective interventions, http://www8.utsouthwestern.edu/utsw/cda/ dept156726/files/181124.html (these also were provided as hard copy). In addition, TDH recruited a number of providers who volunteered to receive training on topics related to intervention selection and implementation (described in the next section).

Where do contractor staff get intervention ideas? (Table III). Respondents indicated that they most often got ideas for interventions from other providers, while the research literature and theory-driven intervention development were rarely mentioned. This pattern is in consistence with other research with HIV service providers (Goldstein et al., 1998). Texas responded by asking eight prevention providers to participate in an intensive training and TA program. These providers represented a cross section of the State with respect to agency size, length of operation, and urban vs. rural location. The training and TA included courses on behavioral theories, community assessment techniques to identify behavioral determinants of risk, and the use of theory and data to identify and adapt evidence-based interventions for local needs. These providers subsequently acted as peer leaders/TA providers in their local areas. These efforts were supplemented with web-based resources that included a complete community assessment guide, fact sheets for effective interventions (searchable by population and behavioral theory), and a variety of data, planning, and evaluation resources (http://www8.utsouthwestern.edu/utsw/cda/ dept156726/files/181124.html) which were made available to all. The website also has a moderated discussion group and a "tip of the month" to promote repeated visits to the site.

Kinds of information that providers feel help them do better work (Table III). Weak links were articulated between the choice of intervention and factors that providers' believed influenced their clients' risk behaviors. The web resources noted previously were designed to help address this gap, as well as the previously described training provided to prevention providers.

Kinds of data currently used by providers to make programming decisions (Table III). Providers most often indicated that they used morbidity data, HIV risk behavior data, and information from conference presentations. Cost effectiveness data, research journals, and qualitative data were very seldom used. Supervisors indicated that they would like to conduct community assessments but rarely did so. In response to this, the previously men- tioned website was designed to offer linkages to costeffectiveness studies and summaries of information normally treated in journal articles (e.g., descriptions of effective interventions), as well as access to the community assessment guide. The website also contains links to resources for intervention materials and training/TA resources. The trained peer leaders (described previously) were seen as another way of disseminating and reinforcing these methods in practice.

\section{CONCLUSIONS/IMPLICATIONS}

The major concerns expressed in both Massachusetts and Texas centered on needs for locally specific data and TA for data use. In addition, the findings from both states underscored the importance of organizational and group process issues (trust, clarity of roles and responsibilities). These findings are remarkable in as much as the two states had very different local conditions and used some differing data collection methods; however, case study evaluations of community planning have obtained similar responses in the past (Batelle, 1995; Renaud and Kresse, 1995, 1996; Research Triangle Institute, 1999; United States Conference of Mayors, 1994, 1998). We attempted to translate the formative assessment findings into concrete action wherever possible, given available resources. The tools and organizational changes that were developed in response to these findings addressed ways to provide more relevant data, while also trying to improve the organizational climate of CPGs and to develop ways to make technical assistance more available on an on-going basis to CPG members.

A number of specific methods for increasing data use came from the formative findings presented here. These included changes in CPG structure, organization, and procedures (Massachusetts); changes in the process for requesting and presenting data (Massachusetts); training in the use of data and behavioral theory (Texas); provision of web-based tools (Texas) and fact sheets (Texas, Massachusetts); development of discussion guides (Texas, Massachusetts); and efforts to help CPG members gain facility with data use by participation in the primary collection and analysis of needs assessment data (Texas), which satisfied a CPG planning requirement (all CPGs in jurisdictions funded by CDC were expected to conduct needs assessments). Massachusetts focused its interventions on its single CPG while Texas, with six CPGs that varied 
widely their data-use capacity, targeted some interventions at CPGs (needs assessment, training of cochairs in applications of data and theory for intervention selection and adaptation), and directed others at prevention providers, an important stakeholder constituency who are usually well represented on CPGs. Given that peers were found to be an important technical assistance resource in Texas and the presence of multiple CPGs with diverse needs limited what Texas could do, a diffusion-based strategy (Rogers, 1995) focused on co-chairs and key stakeholders provided a way to effect peer groups within CPGs.

The needs for attention to organizational issues and TA appeared to be inter-related. There was a need for data use TA that went beyond one-shot didactic training sessions and was integrated into the on-going business of CPGs, where the applications of data to planning tasks could receive elaboration and reinforcement. Previous evaluations of community planning (e.g., Batelle, 1995; Renaud and Kresse, 1995, 1996; Research Triangle Institute, 1999; United States Conference of Mayors, 1994, 1998) have emphasized the need to offer TA to CPG members; however, they have not highlighted researchers TA needs, so that they can effectively present data in ways that foster its use in the planning process. The field of evaluation research has given considerable attention to considering the uses of data and the worldviews of data users (e.g., Patton, 1997; Weiss, 1998a,b), but this has not received much attention in HIV prevention community planning. The importance of group leadership in fostering better data use has been seen as an important component of building organizational climate in other kinds of planning and evaluation activities (e.g., Patton, 1997; Weiss, 1980; 1998a,b), hence, leadership also has to become more sophisticated about how to apply data.

The creation of meaningful opportunities for CPG members to be engaged with data is another approach that cuts across the different needs that were identified here. By collecting local needs assessment and community assessment data (which addressed local gaps in Texas), CPG members can clearly see the value and limitations of data, as well as the roles played by measurement and methodological factors. In Massachusetts, more kinds of data were available, with somewhat less regional variation. Under those conditions, more emphasis was given to working with existing data (the focused discussions about presentations by population-based small groups), improving data presentations (with templates and guided discussion) and developing mechanisms to request data. The effort to engage $\mathrm{CPG}$ members in collection, analysis and/or application of data is likely to increase their understanding of how to deal with technical aspects of data use (e.g., sampling, measurement, etc.), while also adding to the capacity for applying data-based findings to planning tasks. Moreover, this involvement may help in understanding caveats associated with different data (e.g., limitations of reporting, sampling), which can be difficult to explain and can create the impression that available data are of little use or are being manipulated toward a particular end. A final consideration is that TA needs to be provided outside of CPG meetings. The development of web-based resources is an important step in that direction and it is a step which serves the overlapping needs of prevention providers, as well.

\section{Limitations of the Approach Here}

Despite our best efforts to translate the formative assessments into action, some of the most straightforward solutions had limitations. For example, Texas was able to further refine their analyses of morbidity data to provide more information about the demographic characteristics and risk associated with local cases, however, the confidentiality and analytic concerns that go with small numbers of cases limited the breakdowns in some regions. Resources and logistics presented other barriers. For example, the effort to address the confluence of organizational development and technical assistance needs was easiest to address within a single CPG, as existed in Massachusetts.

The two states had considerable overlap in the content of their formative assessment measures, however, there also were differences in terms of the assessment methods that were used (e.g., more emphasis on observation in Massachusetts) and the populations that were sampled (CPG members only in Massachusetts, CPG members and prevention providers in Texas). Consequently, the formative findings may have been different from those presented here if the populations and assessment instruments had been more similar. On the other hand, the geographic characteristics of the states and the demographic and other characteristics of CPG members were different enough that one would expect that different findings would occur and that a variety of considerations (e.g., local capacity) would still require the two jurisdictions to handle even similar local problems in very different ways. 


\section{General Considerations for Community Planning Practice}

The conventional wisdom for addressing the use of data for planning purposes has been to increase the amount of available data or to provide more training, usually in the form of didactic one-shot programs. The findings here suggest the importance of looking at how groups operate and addressing fundamental problems in decision making to improve the use of data. They also suggest that TA needs to address the needs of researchers, as well as to nonresearcher CPG members. Further, the findings from Texas suggest the value of developing tools that can address CPGs and related groups, such as prevention providers, who may have similar data needs. Finally, the tools developed here all point toward considerations that are often missing from the planning process: the need for constituencies who advocate for the planning process and for data. As was evident in these two sites, planning often gets bogged down because of allegiances to populations and agencies, and tensions between the roles of health departments and CPG members. Efforts to provide TA and improve group process need to find ways to make data important to everyone and to focus on the planning tasks. TA that helps CPG members become more involved with data and permits researchers to better address planning tasks with data are important steps in these directions.

The ways in which TA are provided need to be tailored to local resources, planning structures in particular jurisdictions, and other considerations particular to individual planning areas. The case studies here illustrate how common needs may not always lead to the same solutions in all jurisdictions. Here, we have tried to demonstrate how individual jurisdictions can engage in self-study and develop locally relevant ways to reduce barriers to data use. The more general considerations in providing TA are discussed in the companion paper by Jenkins et al. (2005). The desire for "off the shelf" tools unfortunately leads to "uniformity myths" about how to address CPG needs. These "myths" often mean that the needs of a particular setting or population are ignored. Here our concerns focus on the geographic, administrative and resource differences between the states of Massachusetts and Texas. Concerns about "uniformity myths" have been widely considered in the larger literature on behavioral intervention (see Kiesler, 1966 for a historically important example), but have received less attention in public health pol- icy and operations research. We wish to encourage other jurisdictions to adapt the formative assessment and TA tools from this project; however, we also believe that consideration of local conditions is necessary to make the use of these tools useful and successful.

\section{ACKNOWLEDGMENTS}

The authors wish to acknowledge the helpful comments made by Bob Kohmescher, Ann O'Leary, Ron Stall, and two anonymous reviewers on earlier drafts of the manuscript. Assistance with data coding for CDC-directed portions of the data analysis was provided by Danielle German and Erin PiconeDeCaro. Some of the material in this paper was previously been presented at the 2002 and 2003 Community Planning Leadership Councils (in Atlanta and New York, respectively) and at the 2003 US Conference on AIDS in Atlanta, GA. This project was funded under CDC program announcement \#99098.

\section{REFERENCES}

Academy for Educational Development (1994). Handbook for HIV prevention community planning. Washington, DC: Author.

Amaro, H., Conron, K. J., Mitchell, E. M. H., Morrill, A. C., Blake, S. M., and Cranston, K. (2005). HIV prevention community planning: Challenges and opportunities for data-informed decision-making. AIDS and Behavior, this issue.

Batchelor, K., Freeman, A. C., Robbins, A., Dudley, T., and Phillips, N. (2005). A formative assessment of the use of behavioral data in HIV prevention in Texas. AIDS and Behavior, this issue.

Batelle (1995). HIV prevention community planning case studies. Arlington, VA: Author.

Carey, J. W., Wenzel, P. H., Reilly, C., Sheridan, J., and Steinberg, J. M. (1998). CDC EZ-Text: Software For Management And Analysis Of Semi-Structured Qualitative Data sets. Cultural Anthropology Methods, 10, 14-20.

Centers for Disease Control and Prevention (CDC) (1993). Guidance, HIV prevention community planning for HIV prevention cooperative agreement recipients. Atlanta: Author.

Centers for Disease Control and Prevention (CDC) (1998). Guidance, HIV prevention community planning for HIV prevention cooperative agreement recipients. Atlanta: Author.

Centers for Disease Control and Prevention (CDC) (2001). Summary of notifiable diseases, 1999. Morbidity and Mortality Weekly Report, 48, 1-124.

Centers for Disease Control and Prevention (CDC) (2003). HIV prevention community planning guide. Atlanta: Author.

Goldstein, E., Wrubel, J., Faigels, B., and DeCarlo, P. (1998). Sources of information for HIV prevention program managers: A national Survey. AIDS Prevention and Education, 10, 63-74.

Jenkins, R. A., and Carey, J. W. (2005). Special issue: Introduction and background. AIDS and Behavior, this issue. 
Jenkins, R. A., Cranston, K., Robbins, A., Amaro, H., Morrill, A. C., Batchelor, K., Freeman, A. C., Blake, S. M., Logan, J. A., and Carey, J. W. (2005). Improving the use of data for HIV prevention decision making: Lessons learned. AIDS and Behavior, this issue.

Kiesler, D. (1966). Some myths of psychotherapy research and the search for a paradigm. Psychological Bulletin, 65, 110136.

Patton, M. Q. (1997). Utilization-focused evaluation: The new century text. Newbury Park, CA: Sage.

Renaud, M., and Kresse, E. (1995). HIV prevention community planning profiles: Assessing year one. Washington, DC: United States Conference of Mayors.

Renaud, M., and Kresse, E. (1996). HIV prevention community planning profiles: Assessing the impact. Washington, DC: United States Conference of Mayors.

Research Triangle Institute (1999). Final report: An assessment to determine program evaluation technical assistance needs, wants, resources, services, service gaps, and preferred methods of responding to technical assistance requests of health departments, community planning groups, community-based organizations, and CDC staff in the context of HIV prevention. Research Triangle, NC: Author.
Rogers, E. M. (1995). Diffusion of innovations (4th ed.). New York: Free Press.

Rothman, J. (1974). Three models of community organization practice. In F. M. Cox, J. L. Erlich, J. Rothman, and J. E. Tropman (Eds.), Strategies of community organization: $A$ book of readings (pp. 22-38). Itasca, IL: Peacock.

Tversky, A., and Kahneman, D. (1974). Judgment under uncertainty: Heuristics and biases. Science, 185, 1124-1131.

United States Conference of Mayors (1994). HIV prevention community profiles: Assessing the year one. Washington, DC: Author.

United States Conference of Mayors (1998). HIV prevention community profiles: Assessing the process and the evolving effects. Washington, DC: Author.

Valdiserri, R. O., Aultman, T. V., and Curran, J. W. (1995). A national strategy to improve HIV prevention programs. Journal of Community Health, 20, 87-100.

Weiss, C. H. (1980). Social science research and decision-making. New York: Columbia University Press.

Weiss, C. H. (1998a). Have we learned anything new about the use of evaluation? American Journal of Evaluation, 19, 21-33.

Weiss, C. H. (1998b). Evaluation for decisions: Is anybody there? Does anybody care? Evaluation Practice, 9, 5-19. 